\title{
Comparative in vivo antiangiogenic effects of calreticulin from Trypanosoma cruzi and Homo sapiens sapiens
}

\author{
Víctor Toledo ${ }^{1}$ 2, Galia Ramírez' ${ }^{1}$, Carolina Valck ${ }^{1}$, Nandy López ${ }^{1}$, Carolina H Ribeiro ${ }^{1}$, Ismael Maldonado ${ }^{1}$, \\ Lorena Aguilar ${ }^{1}$, David Lemus ${ }^{2}{ }^{*}$ and Arturo Ferreira ${ }^{*}$
}

${ }^{1}$ Laboratory of Immunology of Microbial Aggression. Immunology Disciplinary Program, ICBM, Faculty of Medicine, University of Chile

2 Disciplinary Program of Developmental Anatomy and Biology, ICBM, Faculty of Medicine, University of Chile

\begin{abstract}
Angiogenesis is a complex multi-step process of neovascularization arising from preexisting blood vessels whose generation is regulated by pro- and anti-angiogenic factors. Both Trypanosoma cruzi calreticulin (TcCRT) and its human counterpart (HuCRT) are antiangiogenic. This is the first report where the TcCRT and HuCRT anti-angiogenic properties are compared in vivo. In the chick embryonic chorioallantoid membrane assay (CAM) and at equimolar concentrations, TcCRT displayed significantly higher antiangiogenic activities than its human counterpart. LPS had marginal effects at the concentrations present in the recombinant protein preparations and the TCCRT antiangiogenic effects were largely inhibited by specific polyclonal antibodies, thus, reinforcing the fact that the observed TcCRT effects can be attributed to the parasite-derived molecule and not to the endotoxin. The antiangiogenic TcCRT effects correlate with its anti-tumor in vivo effects, as recently shown in our laboratory.
\end{abstract}

Key terms: Calreticulin, T. cruzi, anti-angiogenesis.

Chagas' disease is a chronic debilitating affliction, of difficult treatment, that in Latin America affects 12 million individuals. In Chile, there are about 150,000 seropositive humans and an indeterminate number of other mammals infected, acting like natural reservoirs of the causal agent, the Trypanosoma cruzi protozoan. It is, therefore, a zoonosis of great relevance and in Latin America it constitutes one of the most important public health problems, with a severe socioeconomic impact (Bastien, 1998).

We have cloned, sequenced and expressed the T. cruzi calreticulin gene (TcCRT) (Aguillon et al., 2000). Its product, TcCRT, is an immunogenic $45 \mathrm{kDa}$ protein, with more than $50 \%$ identity ( $80 \%$ in some functional domains) with the human counterpart (HuCRT). Although it locates preferentially in the ER, it is translocated to the parasitic surface, mainly to areas adjacent to the flagellum emergence (Ferreira et al., 2004). TcCRT and HuCRT are also functionally homologous, including negative regulation of the human complement system (Ferreira et al., 2004; Valck et al., 2010) As a consequence, they promote parasite infectivity (Ramirez et al., 2010).

HuCRT is a highly conserved $46-\mathrm{kDa}$ calcium-binding pleiotropic protein present in virtually all nucleated cells of higher organisms. It is located preferentially in the ER (Michalak et al., 1992; Ostwald and MacLennan, 1974), and regulates a series of cellular functions (Fraser et al., 2000; Michalak et al., 1999). Peptides derived from HuCRT, located between amino acids 120-180 (vasostatin), as well as the whole molecule, display antiangiogenic properties in vivo and in vitro (Cheng et al., 2001; Pike et al., 1998). These molecules also have antitumor effects (Pike et al., 1999).

TCCRT is a powerful angiogenesis inhibitor in vivo, in the chick embryonic chorioallantoid membrane assay (CAM) of Gallus gallus (Aguilar et al., 2005). There has been speculation for decades on the possible mechanisms involved in the in vivo effects that infection with several T. cruzi strains may have on a variety of transplanted and spontaneous tumors in animals and humans (Galliard et al., 1950; Oliveira et al., 2001; Roskin, 1946). Given the evolutionary distance between Trypanosoma and Homo species and the differences in primary sequences between their CRTs, it is of interest to define, in vivo, the comparative efficiency in equimolar terms of these molecules to mediate antiangiogenic function. The results may contribute to understanding whether the antiangiogenic properties were first consolidated in the parasite chaperone molecule and then HuCRT conserved some of these properties as an evolutionary relict, or alternatively, the parasite "hijacked" this activity from its vertebrate host.

Figure 1 summarizes in vivo results obtained in the CAM assay, performed as described (Aguilar et al., 2005), when the antiangiogenic properties of TcCRT and HuCRT were compared in equivalent terms. Briefly, $10 \mu \mathrm{l}$ containing different concentrations (10pg to 10ng) of rHuCRT and rTcCRT were added on the filters placed on the chicken egg CAM (White Leghorn, Institute of Public Health, Santiago, Chile), Betamethasone (Lemus et al., 2001) and ovoalbumin were used as positive and negative controls, respectively. A significant difference was observed between both controls and between the human and parasite chaperone molecules, the latter displaying stronger effects, in concentrations ranging from $10 \mathrm{pg}$ to $10 \mathrm{ng}$ ( $\mathrm{p}<0.05)$.

LPS, a known antiangiogenic molecule (Zetter, 1998) and ubiquous contaminant in E. coli- derived recombinant proteins, was tested in the CAM assay in concentrations similar to those present in HuCRT and TcCRT. Under these conditions, the endotoxin had marginal effects (results not shown). This result, together with the fact that polyclonal antirTcCRT IgG strongly inhibited the anti-angiogenic effects mediated by the parasite molecule (Figure 2), substantiates the specificity of the antiangiogenic TcCRT property.

* Corresponding Authors: Arturo Ferreira, David Lemus. Address: Independence 1027, Independence, Santiago, Chile. Email address: aferreir@med.uchile.cl. dlemus@med.uchile.cl. Phone Number: 56-2-9786423. Fax Number: 56-2-9786979

Received: December 12, 2009. In revised form: May 24, 2010. Accepted: June 8, 2010. 


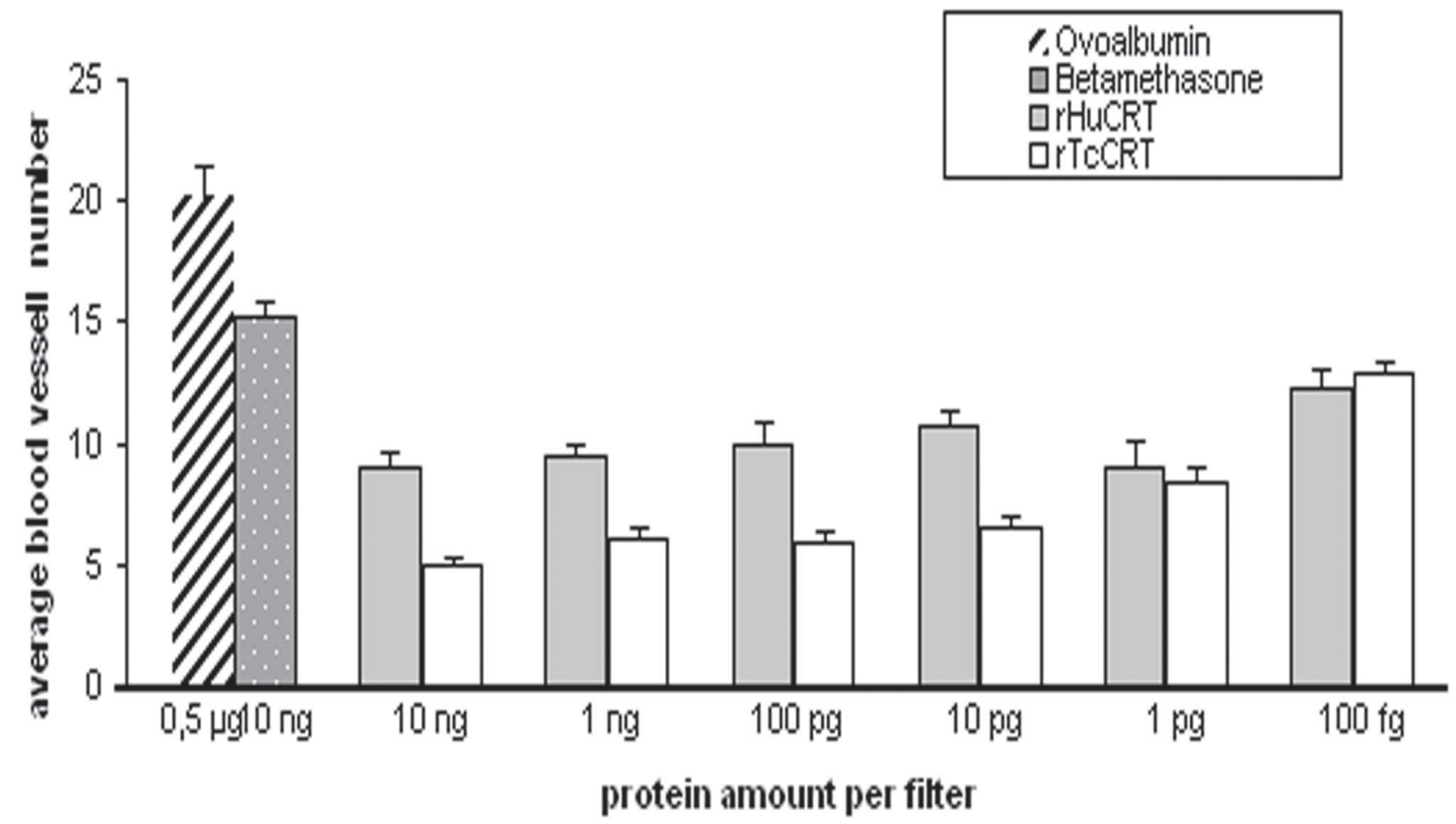

Figure 1: rTCRT mediates a stronger antiangiogenic effect than rHuCRT in the CAM assay. The fertilized eggs were incubated for 10 days at $38.5{ }^{\circ} \mathrm{C}$. Then, sterile methyl cellulose filters were deposited on the CAMs. On each filter, TCCRT or HuCRT were added at equimolar concentrations. After incubating for an additional $72 \mathrm{~h}$, the number of blood vessels present in $9000 \mu \mathrm{m}^{2}$ was counted, in a double blind procedure, by conventional light microscopy. Bethamethasone and ovoalbumin were used as positive and negative angiogenesis controls, respectively. Data were analyzed by ANOVA and Tukey tests. Results were expressed as means and their standard deviations.

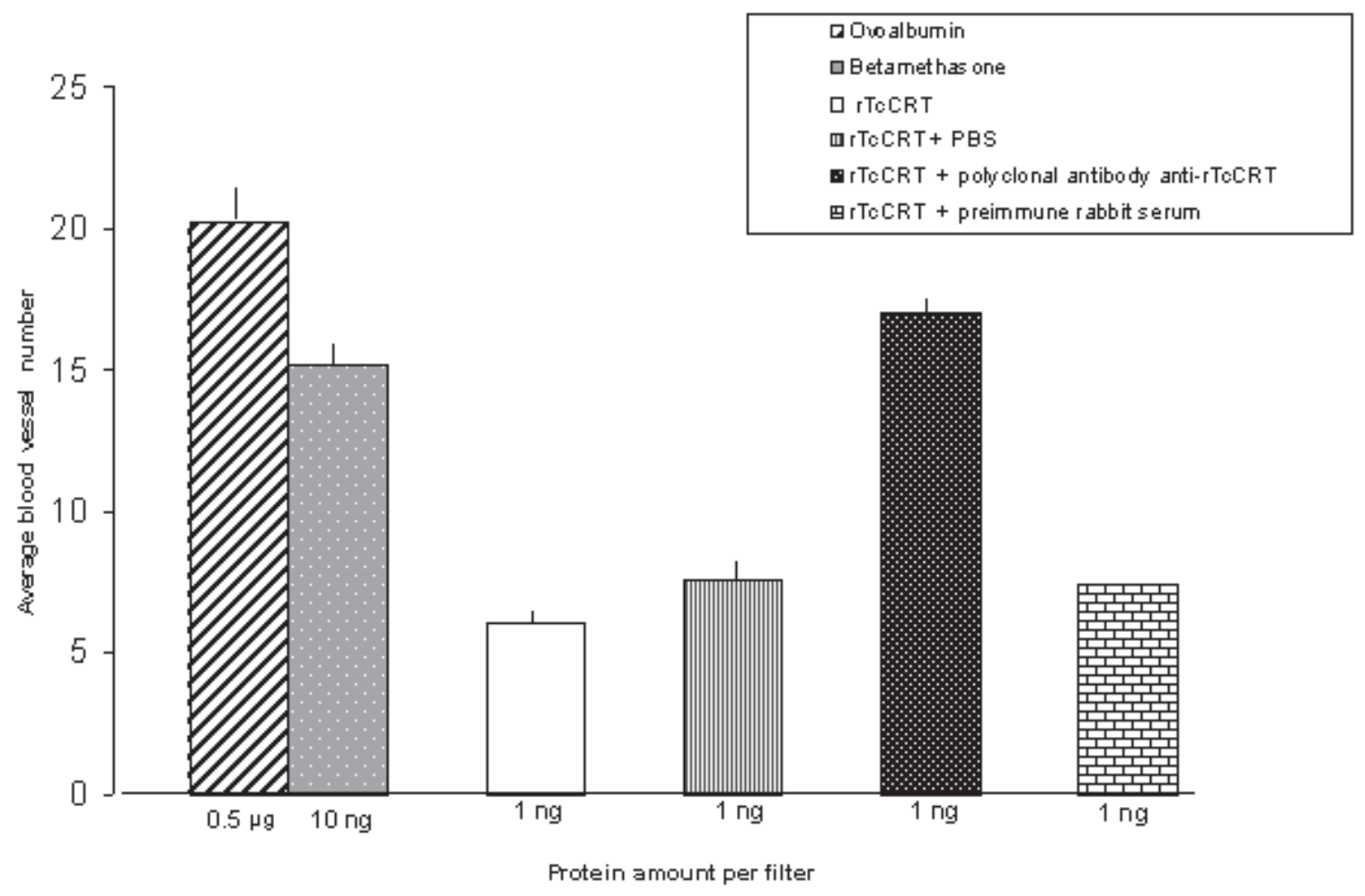

Figure 2: The antiangiogenic rTcCRT effect is inhibited by polyclonal anti-rTcCRT antibodies. Before its addition to the filters, TcCRT was incubated with rabbit polyclonal anti-TCCRT antibodies. Preimmune serum or PBS was used as controls. Data were analyzed by ANOVA and Tukey tests. Results were expressed as means and their standard deviations. 
TcCRT, in primary cultures of human endothelial cells, inhibits three fundamental stages of the angiogenic process (migration, proliferation and morphogenesis). In general, in these assays, and also in the ex vivo rat aortic ring test, the parasite molecule was more effective than the human counterpart (López et al., 2010). The N-terminal TcCRT domain reproduced these effects (unpublished observations). The in vivo results presented here agree with those in vitro and ex vivo studies. Recently (López et al., 2010), it has been determined in vitro that TCCRT enters the endothelial cell and locates perinuclearly. It remains to be defined if this access is a prerequisite for the antiangiogenic TcCRT effect.

The stronger antiangiogenic rTcCRT efficiency, as compared to HuCRT, may have emerged in protozoan forms, as a necessary consequence of their interactions with contemporary vertebrate hosts. The conservation of these functions in HuCRT could represent a non-deleterious evolutionary relict. These TCCRT antiangiogenic and complement inhibitory properties in the parasite may have consolidated to decrease inflammation on the sites of parasite locations, thus impairing the potential immune system capacity to destroy them. Alternatively or concomitantly, since angiogenesis is essential for tumor growth and metastasis, antiangiogenesis would protect the host from these potent neoplastic aggressors, with obvious possible benefits for the parasite. Indeed, there has been speculation for decades about the possible mechanisms involved in the in vivo experimental protective effects thatinfection with several $T$. cruzi strains may have on a variety of transplanted and spontaneous tumors, in animals and humans. Secretion by the parasite of "toxic substances" for tumors was proposed (Galliard et al., 1950; Oliveira et al., 2001). In agreement with our results, one such substance may be TcCRT. On the other hand, in the pathogenesis of the chronic inflammatory disease, the immune response triggered by the parasite seems to be an important component (Kierszenbaum, 2005). Moreover, inflammation is an essential part in the protective response against the infection (Pinedo et al., 1998; Teixeira et al., 2002). Thus, the antiangiogenic effect mediated by $T$. cruzi calreticulin may finally result in both, protection for the parasite and, as a collateral effect, indirectly benefiting the parasite, protection for the host.

\section{REFERENCES}

AGUILAR L, RAMÍREZ G, VALCK C, MOLINA MC, ROJAS A, SCHWAEBLE $\mathrm{W}$, FERREIRA $\mathrm{V}$ and FERREIRA A (2005) $\mathrm{F}\left(\mathrm{ab}^{\prime}\right) 2$ antibody fragments against Trypanosoma cruzi calreticulin inhibit its interaction with the first component of human complement. Biol Res 38, 187-95.

AGUILLON JC, FERREIRA L, PÉREZ C, COLOMBO A, MOLINA MC, WALLACE A, SOLARI A, CARVALLO P, GALINDO M, GALANTI N, ORN A, BILLETTA R and FERREIRA A (2000) Tc45, a dimorphic Trypanosoma cruzi immunogen with variable chromosomal localization, is calreticulin. Am J Trop Med Hyg 63, 306-12.

BASTIEN JW (1998) The Kiss of Death: Chagas Disease in the Americas. University of Utah Press, Salt Lake City.
CHENG WF, HUNG CF, CHAI CY, HSU KF, HE L, LING M and WU TC (2001) Tumor-specific immunity and antiangiogenesis generated by a DNA vaccine encoding calreticulin linked to a tumor antigen. J Clin Invest 108, 669-78.

FERREIRA V, VALCK C, SÁNCHEZ G, GINGRAS A, TZIMA S, MOLINA MC, SIM R, SCHWAEBLE W and FERREIRA A (2004) The classical activation pathway of the human complement system is specifically inhibited by calreticulin from Trypanosoma cruzi. J Immunol 172, 304250.

FRASER SA, KARIMI R, MICHALAK M and HUDIG D (2000) Perforin lytic activity is controlled by calreticulin. J Immunol 164, 4150-5.

GALLIARD H, BRUMPT L and MARTÍNEZ R (1950) Infections Expérimentales a Trypanosoma cruzi Chagas chez 1' homme a propos de la biotherapie du cancer. Bull Soc Path Exot 43, 204-216.

KIERSZENBAUM F (2005) Where do we stand on the autoimmunity hypothesis of Chagas disease? Trends Parasitol 21, 513-6.

LEMUS D, DABANCENS A, ILLANES J, FUENZALIDA M, GUERRERO A and LÓPEZ C (2001) Antiangiogenic effect of betamethasone on the chick cam stimulated by TA3 tumor supernatant. Biol Res 34, 22736.

LÓPEZ N, VALCK C, RAMÍREZ G, RODRÍGUEZ M, RIBEIRO $\mathrm{CH}_{\text {, }}$ ORELLANA J, MALDONADO I, ALBINI A, ANACONA D, LEMUS D, AGUILAR L, SCHWAEBLE $W$ and FERREIRA A (2010) Antiangiogenic and Antitumor Effects of Trypanosoma cruzi Calreticulin. PLoS Negl Trop Dis In Press.

MICHALAK M, CORBETT EF, MESAELI N, NAKAMURA K and OPAS M (1999) Calreticulin: one protein, one gene, many functions. Biochem J 344 Pt 2, 281-92.

MICHALAK M, MILNER RE, BURNS K and OPAS M (1992) Calreticulin. Biochem J 285 ( Pt 3), 681-92.

OLIVEIRA EC, LEITE M. S, MIRANDA JA, ANDRADE AL, GARCÍA SB, LUQUETTI A O and MOREIRA H (2001) Chronic Trypanosoma cruzi infection associated with low incidence of 1,2-dimethylhydrazineinduced colon cancer in rats. Carcinogenesis 22, 737-40.

OSTWALD TJ and MACLENNAN DH (1974) Isolation of a high affinity calcium-binding protein from sarcoplasmic reticulum. J Biol Chem $249,974-9$.

PIKE SE, YAO L, JONES KD, CHERNEY B, APPELLA E, SAKAGUCHI K, NAKHASI H, TERUYA-FELDSTEIN J, WIRTH P, GUPTA G and TOSATO G (1998) Vasostatin, a calreticulin fragment, inhibits angiogenesis and suppresses tumor growth. J Exp Med 188, 2349-56.

PIKE SE, YAO L, SETSUDA J, JONES KD, CHERNEY B, APPELLA E, SAKAGUCHI K, NAKHASI H, ATREYA CD, TERUYA-FELDSTEIN J, WIRTH P, GUPTA G and TOSATO G (1999) Calreticulin and calreticulin fragments are endothelial cell inhibitors that suppress tumor growth. Blood 94, 2461-8.

PINEDO HM, VERHEUL HM, D'AMATO RJ and FOLKMAN J (1998) Involvement of platelets in tumour angiogenesis? Lancet 352, 1775-7.

RAMÍREZ G, VALCK C, MOLINA MC, RIBEIRO CH, LOPEZ N, SANCHEZ G, FERREIRA VP, BILLETTA R, AGUILAR L, MALDONADO I, CATTAN P, SCHWAEBLE $\mathrm{W}$ and FERREIRA A (2010) Trypanosoma cruzi calreticulin: A novel virulence factor that binds complement $\mathrm{C} 1$ on the parasite surface and promotes infectivity. Immunobiology In Press.

ROSKIN G (1946) Toxin therapy of experimental cancer; the influence of protozoan infections upon transplanted cancer. Am Rev Sov Med 4, 111-5.

TEIXEIRA MM, GAZZINELLI RT and SILVA JS (2002) Chemokines, inflammation and Trypanosoma cruzi infection. Trends Parasitol 18, 262-5.

VALCK C, RAMÍREZ G, LÓPEZ N, RIBEIRO CH, MALDONADO I, SANCHEZ G, FERREIRA VP, SCHWAEBLE $W$ and FERREIRA A (2010) Molecular mechanisms involved in the inactivation of the first component of human complement by Trypanosoma cruzi calreticulin. Mol Immunol 47, 1516-21.

ZETTER BR (1998) Angiogenesis and tumor metastasis. Annu Rev Med 49, $407-24$. 
